\title{
TURBINE MODEL USED FOR ENERGY CONVERSION IN RIVER WATER STREAMS
}

\author{
Assistant professor Fanel SCHEAUA, PhD Eng \\ "Dunărea de Jos" University of Galați \\ "MECMET" Research Center
}

\begin{abstract}
The water flow potential in rivers represents significant resources for aquiring cheap energy production. Depending on the three essential parameters of water flow rate, stream velocity and level difference, optimal constructive solutions are usually adopted for choosing the turbine type to be used in order to obtain energy in a hydroelectric power plant. A three-dimensional turbine model has been developed describing the real rotor model which has the possibility of being directly mounted on the water course in order to take over a part from the water energy and to obtain rotational motion at the rotor axis. A water flow analysis is performed in the fluid area built around the rotor model and the results obtained are presented as values for the water flow rate, velocity and water pressure registered within the fluid area.
\end{abstract}

KEYWORDS: hydro power plant, turbine model, fluid flow, three-dimensional modeling, CFD

\section{INTRODUCTION}

The potential of a water stream having a consistent flow rate can be taken into account in order to obtain energy by the use of special construction rotor turbines.

Due to the constant increase in energy demand, all possibilities of energy production have to be taken into account, especially when using the water flows energy which is an efficient but also environment friendly solution where turbine installation is possible.

A turbine model having a horizontal axis is shown in this paper, being adopted as a solution to be applied in the case of water flows to obtain electrical energy by the rotational movement obtained at the turbine shaft by using a water flow for rotor driving.

The basic concept of this constructive water turbine solution is not an environment invasive solution because it can be easily mounted on the water course without the need of a complex construction.

\section{ASPECTS OF THE OPERATION PRINCIPLE}

The water turbine assembly model has the ability of rotational motion around its own axis based on the force exerted by the direct water flow on the longitudinal rotor blade of the turbine.

The energy production through the use of water turbines is possible by converting the water 
mechanical energy in rotational motion to the rotor shaft by the direct action of the hydrostatic forces acting successively on the rotor blades.

Due to the level differences between turbine upstream and downstream positions, water has the flow potential under the ground gravity direct effect.

The water amount is given by the flow rate in time unit through the section of the river bed.

The flow rate is a variable amount over time depending on the meteorological factors involved in the surface water circulation.

For the energy conversion process that takes place at the water turbine level, it is necessary to know the value of the water flow velocity, a major importance parameter for the turbine unit efficiency.

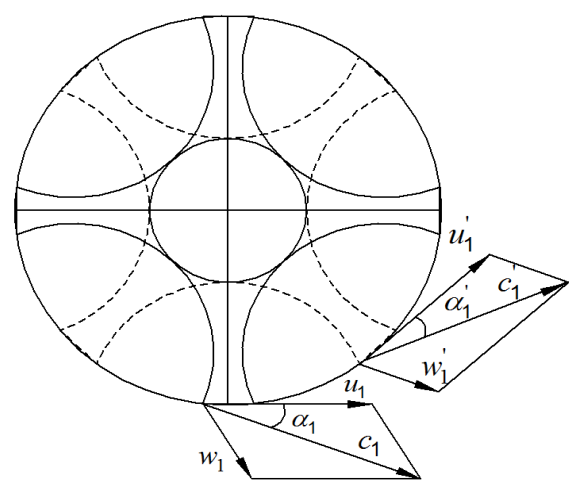

Figure $1 \quad$ Turbine rotor assembly schematic representation

The rotor model is schematically shown in Figure 1, being a four-bladed model belonging to the action turbine group having the ability to sequentially take over the water, ensuring the required shaft rotation movement using the water flow.

The positioning solution for this rotor model in the working front can only be achieved in the horizontal direction.

The turbine rotor can be freely moved by water, being positioned with the shaft at the water surface so that the water is able to develop pressure forces over the entire surface of the blade positioned at the rotor bottom.

\section{TURBINE ASSEMBLY MODEL}

A three-dimensional overall design for the water turbine rotor has been achieved with the Solid Edge V20 program.

It is a turbine model with a 4-bladed profiled rotor having an outside diameter of $3 \mathrm{~m}$ and a length of $5 \mathrm{~m}$.

This rotor model can be built and mounted directly on the course of the flowing water in order to obtain shaft rotation and generate electricity based on this motion.

It has the advantage of not having a difficult construction, and the assembly system in the working position can also be accomplished without difficulty.

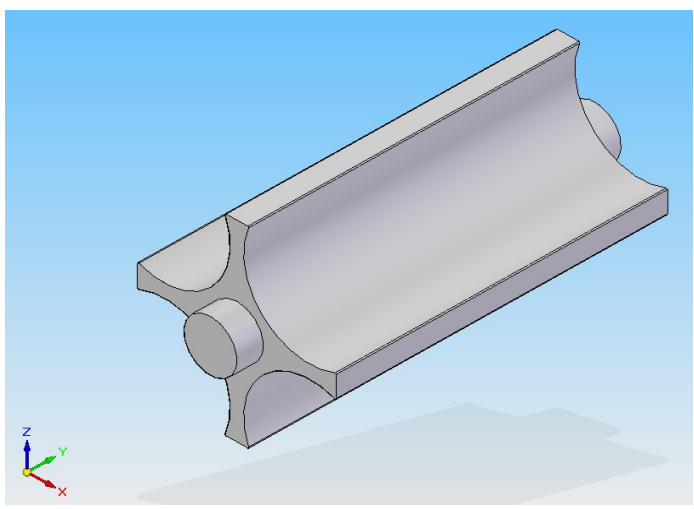

a) water turbine rotor

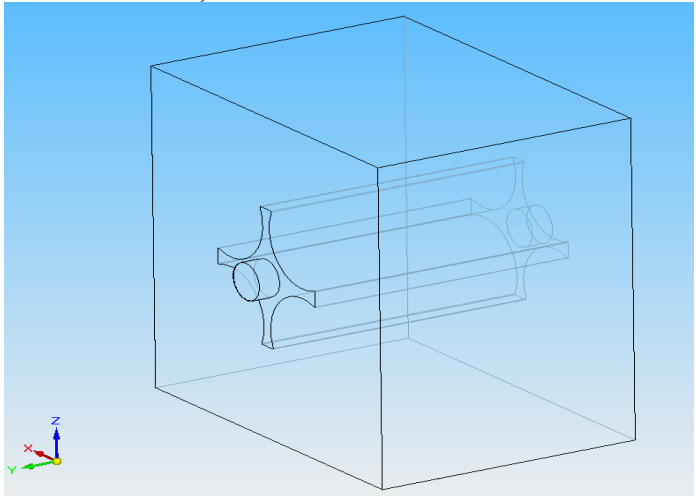

b) assembly with rotor and enclosure

Figure 2 Three-dimensional model for the water turbine and enclosure model

The presented turbine model represents a solution for converting the water flow energy into mechanical rotation energy at the turbine shaft.

The water flow is taken over to the turbine rotor blades because this turbine model is located directly on the water course by diving to the pallet filling limit positioned below the rotor shaft. Thus, the water flow is directed to the rotor blade so that by water action hydrostatic forces are formed on the rotor blade in the normal direction which acts successively on the blades ensuring the continuous rotation of the turbine and the shaft.

Thus, a considerable amount of energy is obtained based on the water flow. 


\section{CFD ANALYSIS FOR TURBINE MODEL}

The analysis is carried out using the ANSYS CFX Academic program.

Starting from the virtual model of the turbine rotor built using the Solid Edge V20 program, a water flow analysis was carried out inside the enclosure containing the rotor.

Water flow analysis is performed by declaring the initial water inlet fluid velocity rate and the calculations are performed to determine the water pressure and velocity values that can determine the rotation movement of the turbine rotor. Thus, the results are presented which describe the water flow regime on the analyzed fluid region.

The analysis is carried out using the ANSYS CFX Academic program.

For the fluid region, water is declared as working fluid, having a flow rate of $1 \mathrm{~m} / \mathrm{s}$ at the inlet.

The water flow rate determines a forced rotation movement on the turbine shaft by direct action on the turbine blades.

The water inlet was declared on the rectangular area built on the fluid area containing the turbine rotor, having the input area on one side and the exit area on the opposite side.

Figure 3 shows the water turbine rotor assembly model as well as the mesh model for the fluid and rotor assembly with 313724 knots and 1550348 triangular shaped elements.

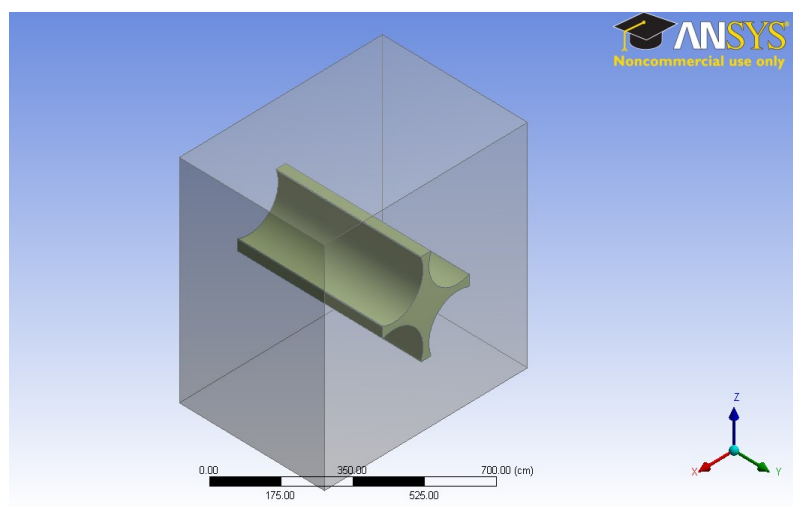

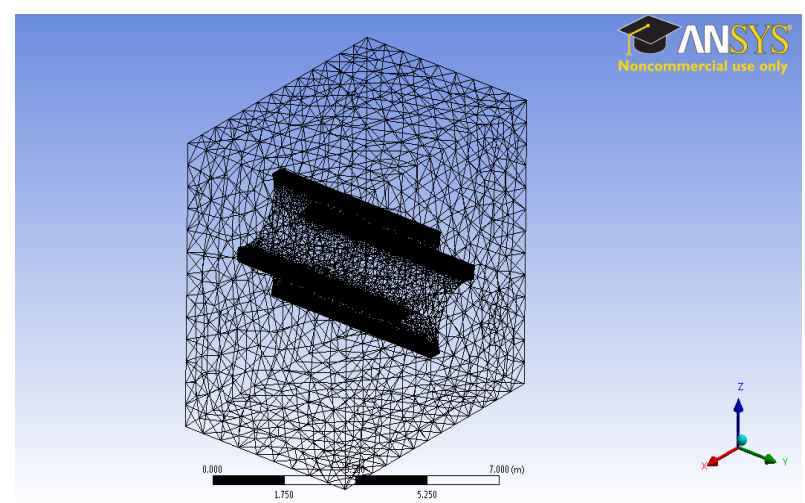

Figure 3 Enclosure and turbine assembly analyzed model and mesh network

The analysis was of the transient type having a total time of 1 second with time steps of $0.1 \mathrm{~s}$.

The fluid region contains two types of fluids, one being represented by air at a reference temperature of 25 degrees Celsius, and the other being water, (figure 4.a).

For fluid models, the k-epsilon options for turbulence were declared, and for the initialization a reference pressure of 1 at was adopted.

The solid domain is represented by the rotor, declared as an immersed solid in the fluid region whose rotation motion is set at $1 \mathrm{rev} / \mathrm{sec}$ around its own axis, (figure 4.b).

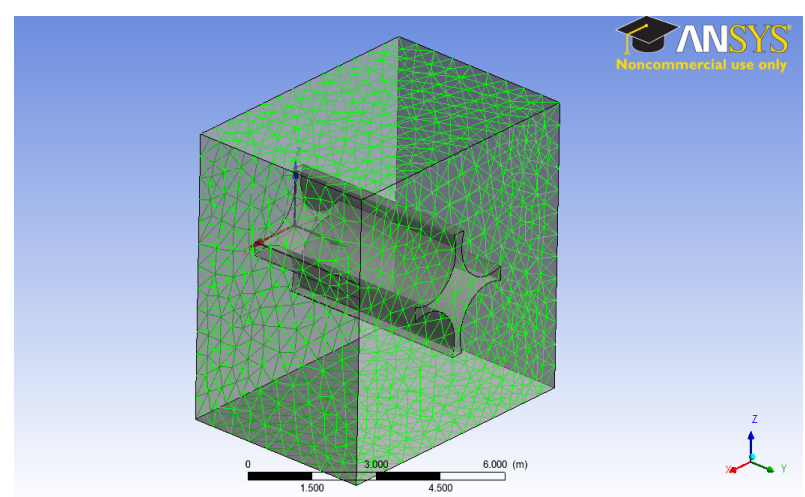

a) fluid region 


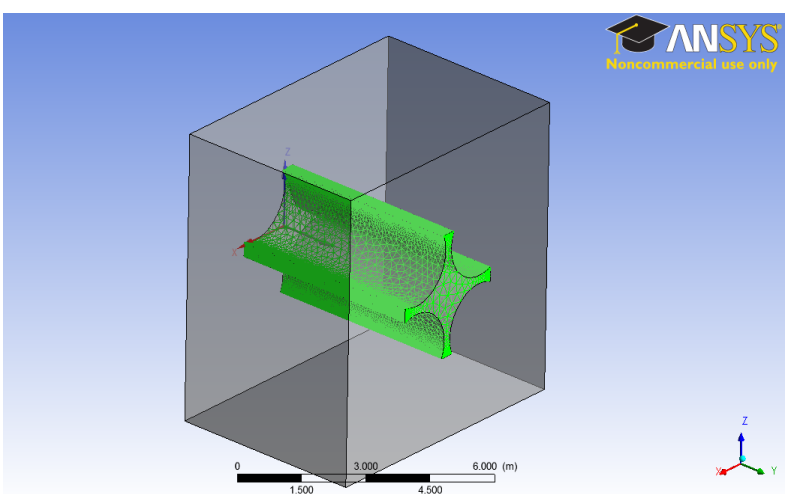

b) rotor as immersed solid

Figure 4 Analysis of main domains

The results obtained from the analysis are presented in terms of fluid superficial velocity, water velocity, fluid volume fraction and absolute pressure on the fluid region (figure 5).

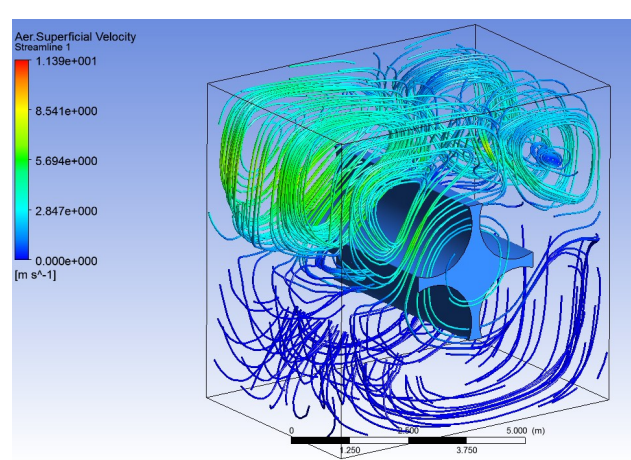

CANS

a) air superficial velocity values

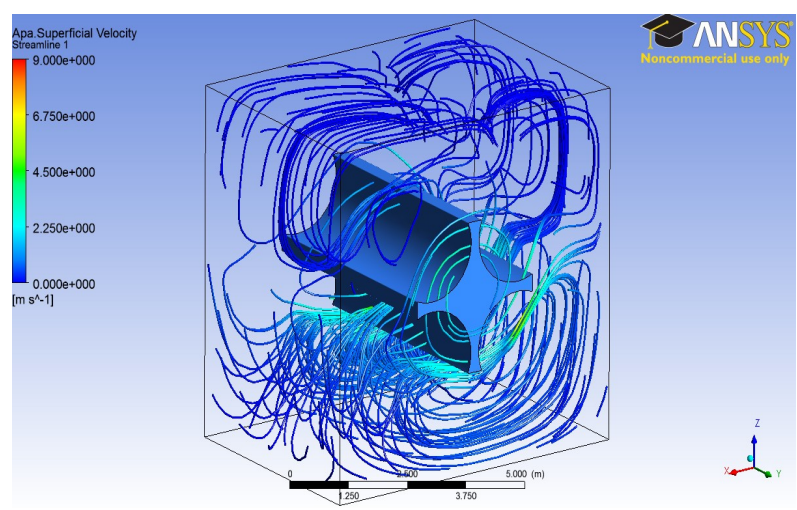

b) water superficial velocity values

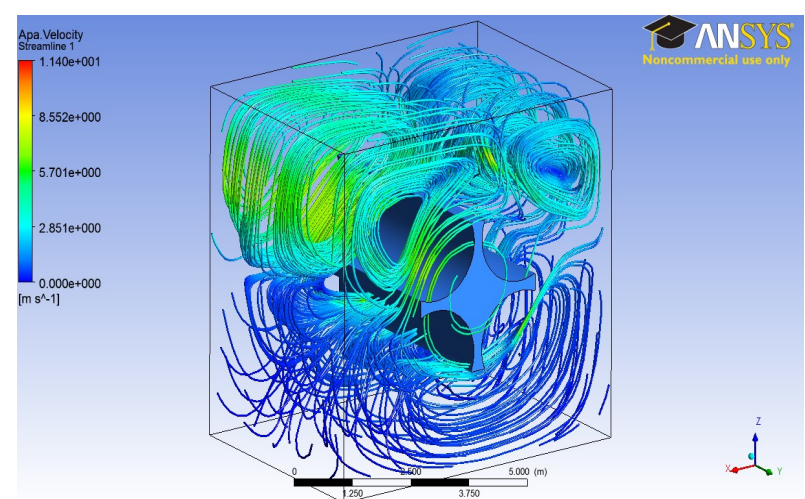

c) water velocity

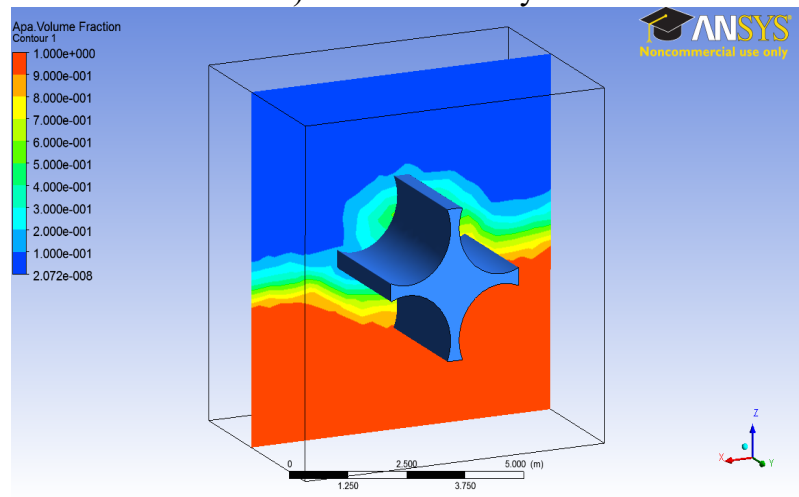

d) water volume fraction

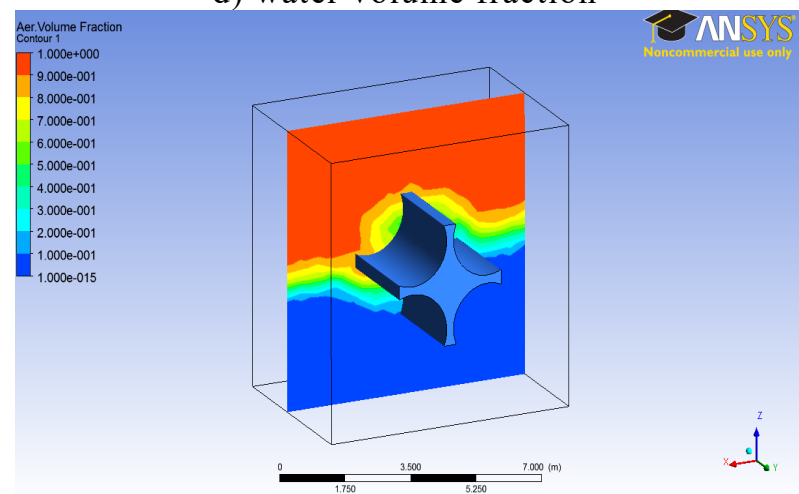

e) air volume fraction

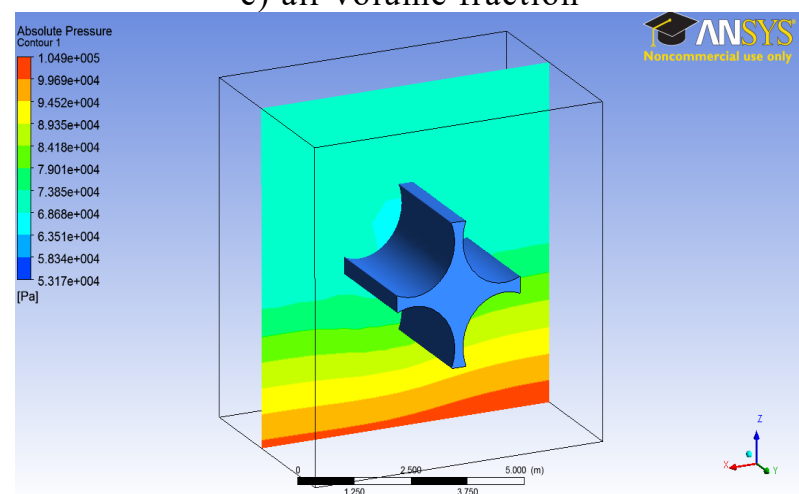

f) absolute pressure values

Figure 5 The values obtained on exit

The results indicate specific values calculated for the basic flow parameters 
represented by fluid velocity and pressure, on the main analysis domains represented by the fluid region and the turbine rotor considered as immersed solid.

The fluid region contains 245 cubic meters of water, the range of pressure values on the fluid enclosure containing the turbine rotor is $104900 \mathrm{~Pa}$, the water mass flow rate is 3869.38 $\mathrm{kg} / \mathrm{s}$.

The total water pressure on the turbine rotor blades is $4334.65 \mathrm{~N}$.

The absolute water pressure on the turbine rotor was calculated at $31199.4 \mathrm{~Pa}$.

\section{CONCLUSION}

Hydro power plants are in operation for a long period of time all over the world ensuring the energy needs for human communities.

Over time, various turbine models working on water strength have been designed and developed.

In this work, a special model for a turbine rotor was designed and analyzed from the point of view of the water action on the virtual model.

The obtained values represent specific values of the water flow rate as direct action on the rotor blades required for shaft rotation.

\section{REFERENCES}

[1] S. Axinti, F. D. Scheaua, "Introducere în hidraulica industrială", ISBN 978-606-696-032-8, Editura Galati University Press, Galati 2015

[2] G. Axinti, A. S. Axinti, "Acţionări hidraulice şi pneumatice", Vol I-V, Aditura Tehnica-Info, Chişinău, 2008-2012

[3] P. G. Kiselev, "Îndreptar pentru calcule hidraulice”, Editura Tehnică, București, 1988

[4] http://www.learnengineering.org/2013 